\title{
Geographical Information System Tool Monitoring the Environmental Impact of Tangier Industrial Zones
}

\author{
Boutaina Sebbah, Miriam Wahbi, Mustapha Maâtouk \\ Department of Geology, Faculty of Science and Technology, AbdelmalekEssaâdi University. \\ Geomatics and Land Development research group \\ Tangier, Morocco \\ boutainasebbah@gmail.com
}

\begin{abstract}
Tangier city is classified as Moroccan second economic center after Casablanca, with three classical industrial zones and two free zones. This industrial activity is expected to increase in the next few years, especially with the implementation of new industrial areas such as "Tangier Automotive City".

Although this intense manufacturing activity is essential for the city development, it has also a direct impact on the environment; one of the major changes caused by the industrial activity is the rising of surface temperatures in industrial zones compared to their surrounding areas.

This study retrieves Land Surface Temperature (LST), from three different Landsat sensors (i.e. TM, ETM+ and OLI-TIRS), using remote sensing algorithms (e.g. Land Surface Temperature, etc.) and a semiAutomatic Classification algorithm, in order to detect temperature variation in Tangier industrial areas during summer months over period between 2000 and 2016.

Results show, that the industrial zones in Tangier city (TFZ and Industrial zone of Meghogha) appear $5^{\circ} \mathrm{C}$ warmer than their surroundings areas, with the presence of major plants that have the highest temperature values comparing to other plants such as (YAZAKI Morocco, S.E.B.N and Delphi Packard Electric) in TFZ and (Jacob Delafon) in Meghogha industrial zone.
\end{abstract}

Keywords: Landsat, semi-Automatic Classification, Land Surface Temperature.

\section{Introduction}

Urbanization process is characterized by the replacement of natural surfaces by anthropogenic ones (e.g. buildings, industries...etc.) [1], [2], which alters radically the aerodynamic, radiative, thermal and moisture properties of urban areas [3],this process is related directly to the economic and industrialization development, and also to the population growth.

According to the general census conducted in Morocco in 2014, The urbanization rate in Tangier city has reached its maximum compared to other major cities (i.e. 94.34\% against 90.5\% in 2004)[4]

The city of Tangier (north of morocco) has also know an important modification in terms of industrial activity during the last decades, and it has become the second Moroccan economic center after 
Boutaina Sebbah, Miriam Wahbi, Mustapha Maâtouk, Geographical Information System Tool Monitoring the Environmental Impact of Tangier Industrial Zones. Transactions on Machine Learning and Artificial Intelligence, Vol 5 No 4 August (2017); p: 795--802

Casablanca city, with diversified industrial activity (e.g. textile, chemical, mechanical, and metallurgical industries)

Tangier has currently five industrial zones, three normal industrial zones (i.e. Industrial zone of Moghogha, Industrial zone of Gueznaya and Al majd Industrial zone) and two specific ones (i.e. Tangier Free Zone and Renault Tanger Med)[5]. In march 2016 Morocco has lunched the colossal project "Cité Mohammed VI Tanger Tech", It is a large industrial and commercial park that will involves the installation of 200 Chinese companies operating in emerging sectors such as automotive and aeronautical industry, aviation spare parts, new information and communication technologies, textiles, machinery manufacturing and other industries.

This industrial growth is indispensable for the development of the city and the entire northern region, view its positive economic and social results, but it is also accompanied by some drastic environmental degradation (e.g. air and water pollution, energy consumption... etc.).

In contrast to urban heat islands which refers to the phenomenon that urban areas tend to have higher atmospheric or surface temperatures compared to simultaneous temperatures of the non-urbanized surrounding areas [2], [6]-[8], industrial zones tend to appear as isolated "hot spots" called micro-urban heat islands [9], this elevation of industrial Land surface temperature (LST) is due in most of cases to construction materials used in industrial zones, high energy consumption and activities type.

Thermal remote sensing data have been largely used to study LST variation around the world, the combination of Geographical Information Systems (GIS) and remote sensing data can be used to provide a multi-temporal understanding of temperature change.

In the present study LST was retrieved, from three different Landsat sensors (i.e. TM, ETM+ and OLI-TIRS), using remote sensing algorithms (e.g. Land Surface Temperature, etc.) and a semi-Automatic Classification algorithm, in order to monitor and assess the spatio-temporal changes of LST in two Tangier industrial zones (i.e. TFZ and Mghogha) during summer months over period between 2000 and 2016.

\section{Study Area and Data Base}

Tangieris located in a relatively mounted area, the city center is located at $35^{\circ} 46^{\prime} 1.2^{\prime \prime} \mathrm{N}$ and $5^{\circ} 48^{\prime} 0^{\prime \prime} \mathrm{W}$, it is the second largest city in Morocco with a population of about 1,065,601 inhabitants.

Tangier city has five industrial zones, twoof them were chosen in the present study in order to monitor and asses the difference of LST between thesezones and their surrounding areas (i.e.Tangier free zone, industrial zone of Meghogha) (Fig.1).

In this study, remotely sensed datasets (Level $1 T$ products) over Tangier city were used, the data is acquired by three different thermal sensors (i.e. Landsat $5 \mathrm{TM}$, Landsat $7 \mathrm{ETM}+$ and Landsat $8 \mathrm{TIRS/OLI),}$ from July to September between 2000 and 2016 Table 1,all images bands have a spectral resolution of 30 $\mathrm{m}$ while the thermal band have a spatial resolution of $120 \mathrm{~m}, 100 \mathrm{~m}$, and $60 \mathrm{~m}$ for TM5, ETM+ and TIRS images respectively.

Images with high percentage of cloudy pixels were excluded from the dataset. As a result, 22 images during the summer period from 2000 to 2016 were available (Table.1). 

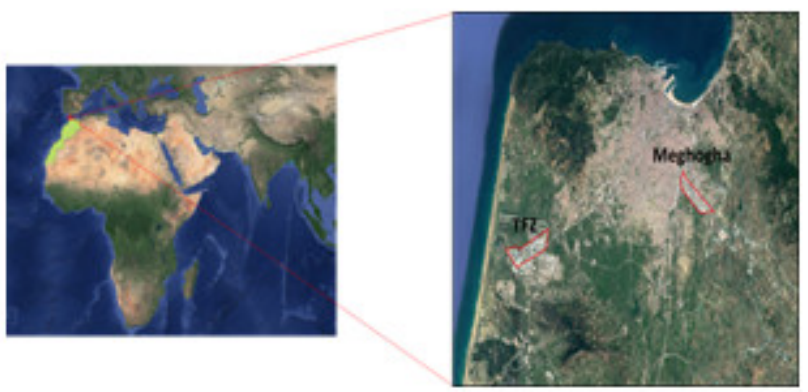

Figure 1. Study area

Table 1. Data Base Available

\begin{tabular}{|c|c|c|c|c|}
\hline Satellite & Year & July & August & September \\
\hline \multirow{3}{*}{ L7 ETM+ } & 2000 & $\checkmark$ & $\checkmark$ & X \\
\cline { 2 - 5 } & 2001 & $\mathrm{X}$ & $\checkmark$ & $\checkmark$ \\
\cline { 2 - 5 } & 2002 & $\checkmark$ & $\checkmark$ & $\checkmark$ \\
\hline \multirow{3}{*}{ L5 TM } & 2009 & $\checkmark$ & $\checkmark$ & $\checkmark$ \\
\cline { 2 - 5 } & 2010 & $\checkmark$ & $\checkmark$ & $\mathrm{X}$ \\
\cline { 2 - 5 } & 2011 & $\checkmark$ & $\mathrm{X}$ & $\checkmark$ \\
\hline \multirow{3}{*}{ L8 OLI/ } & 2013 & $\checkmark$ & $\checkmark$ & $\checkmark$ \\
\cline { 2 - 5 } & 2014 & $\checkmark$ & $\mathrm{X}$ & $\checkmark$ \\
\cline { 2 - 5 } & 2016 & $\checkmark$ & $\checkmark$ & $\checkmark$ \\
\hline
\end{tabular}

3 Methodology

In the present paper LST was retrieved using a semi-automatic classification algorithm under an open GIS software, the hole methodology followed in this study is shown in the flow chart (Figure.2).

\subsection{Conversion from DN to reflectance and at-Satellite temperature}

The Digital Numbers (DN) of each band were converted to Top of Atmosphere (TOA) reflectance (1) (2) [56], then a simple atmospheric correction (i.e. Dark Object Subtraction "DOS1") was applied.

$$
\mathrm{L}_{\lambda}=\mathrm{G}_{\text {rescale }} \times \mathrm{Q}_{\text {cal }}+\mathrm{B}_{\text {rescale }}
$$

Where:

$Q_{\text {cal: }}$ Quantized calibrated pixel value (DN)

$\mathrm{G}_{\text {rescale: }}$ Band-specific rescaling gain factor $[(\mathrm{W} /(\mathrm{m} 2 \mathrm{sr} \mu \mathrm{m})) / \mathrm{DN}]$

$B_{\text {rescale: }}$ Band-specific rescaling bias factor $[\mathrm{W} /(\mathrm{m} 2 \mathrm{sr} \mu \mathrm{m})]$

$$
\mathrm{L}_{\lambda}=\mathrm{M}_{\mathrm{L}} \mathrm{Q}_{\mathrm{cal}}+\mathrm{A}_{\mathrm{L}}
$$

Where:

$L_{\lambda}:$ TOA spectral radiance $\left(\right.$ Watts $\left./\left(\mathrm{m} 2 * \operatorname{srad}^{*} \mu \mathrm{m}\right)\right)$

$M_{\llcorner}:$Band-specific multiplicative rescaling factor from metadata

$\mathrm{Q}_{\text {cal }}:$ Quantized and calibrated standard product pixel values (DN)

$A_{L}$ : Band-specific additive rescaling factor from metadata.

For the thermal band, spectral radiance was converted to At-Satellite Brightness Temperature (3)[10], [11]. Bands 6 and 6-2 were respectively used for Landsat 5 and Landsat 7, while the TIRS bands of Landsat 
Boutaina Sebbah, Miriam Wahbi, Mustapha Maâtouk, Geographical Information System Tool Monitoring the Environmental Impact of Tangier Industrial Zones. Transactions on Machine Learning and Artificial Intelligence, Vol 5 No 4 August (2017); p: 795--802

8 were designed to allow the use of split-window surface temperature retrieval algorithms, but it is recommended for users to avoid data from band 11 for the reason of the large calibration uncertainty of this band[12], thus only band 10 was utilized as a single spectral band.

After the conversion of spectral bands from DN to At-satellite spectral radiance, the thermal band of each satellite was converted to At-Satellite Brightness Temperature (3)[10], [11].

$$
\mathrm{T}=\frac{\mathrm{K} 2}{\ln \left(\frac{\mathrm{K} 1}{\mathrm{~L}_{\lambda}}+1\right)}
$$

WhereK2 and K1 are two pre-launch calibration constants

K1: Band-specific thermal conversion constant (in watts $/ \mathrm{m}^{2} . \mathrm{sr} . \mu \mathrm{m}$ )

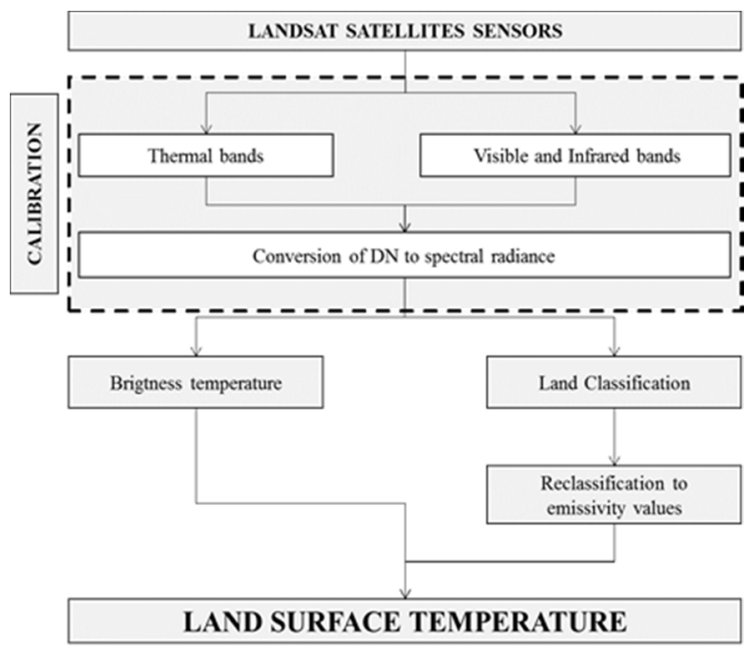

K2: Band-specific thermal conversion constant (in kelvin) Figure 2 Flow chart of the methodology followed

\subsection{Land cover classification of study area}

In order to convert temperature values from At-Satellite Brightness Temperature to Land Surface Temperature, land emissivity values are required, in doing so, the study area was classified into four main classes (i.e. Built-up and minerals, bare soil, vegetation and water) basing on a supervised classification algorithm (i.e. Spectral Angle Mapping algorithm) After the classification ofland cover according four different classes, the obtained rasters were reclassified to emissivity values.

\subsection{Conversion from At Satellite Temperature to Land Surface Temperature.}

The Brightness Temperature values obtained from the application of (3)are temperatures that a blackbody would obtain in order to produce the same radiance at the same wavelength (11.45 for Landsat 5 and 7; 10.8 for Landsat 8). Therefore, corrections for spectral emissivity became necessary according to the nature of land cover. Each land cover class was assigned an emissivity value presented in (Table.II).The emissivity corrected land surface temperatures were computed as follows (4)[13].

Where:

$$
T_{s}=\frac{B T}{\left\{1+\left[\frac{\lambda \cdot B T}{\rho} \cdot \ln \varepsilon\right]\right\}}
$$


Ts: land surface temperature in $\mathrm{K}$;

BT: at-sensor brightness temperature in $\mathrm{K}$

$\lambda$ : wavelength of emitted radiance

$\rho: h c / r=1.438 \cdot 10^{-2} \mathrm{~m} \mathrm{~K}$ with

$\mathrm{h}$ : is the Planck's Constant $\left(6.62610^{-34} \mathrm{Js}^{-1}\right)$

c: is the velocity of light $\left(2.99810^{8} \mathrm{~m} \mathrm{~s}^{-1}\right)$ and $\mathrm{K}$ is Boltzman constant $\left(1.3810^{-23} \mathrm{~J} \mathrm{~K}^{-1}\right)$

$\varepsilon$ : the spectral surface emissivity.

The values of $\lambda$ for the thermal bands of Landsat satellites are listed in (Table. III)

Table 2. Land Surface Emissivity Values Used

\begin{tabular}{|c|c|}
\hline Land surface & Emissivity \\
\hline Built-up & 0.94 \\
\hline Bare soil & 0.95 \\
\hline Vegetation & 0.98 \\
\hline Water & 0.99 \\
\hline
\end{tabular}

Table 3. Center Wavelength of Emitted Radiance of Each Satellite

\begin{tabular}{|l|c|c|}
\hline \multicolumn{1}{|c|}{ Satellite } & Band & Center wavelength \\
\hline Landsat 5 and 7 & 6 & 11.45 \\
\hline Landsat 8 & 10 & 10.8 \\
\hline
\end{tabular}
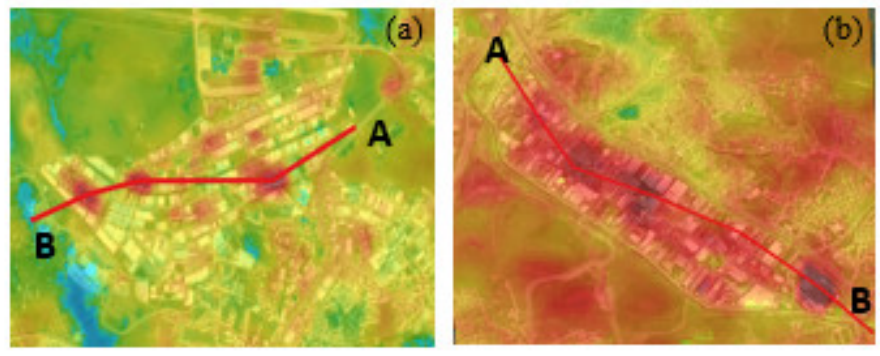

Figure3 Travers pointes of the two studied area; (a) TFZ , (b) Meghogha

\subsection{Calculation of LST variation in industrial zones}

In order to study the difference of LST between thetwo industrial zones (i.e. TFZ and Meghogha) and their surroundings areas, travers points over the studied areas were established (Fig. 3). The values obtained from each traversed pixel were used to plot the variation curves in each studied area from 2000 to 2016, as well as the average curve of LST variation during these 16 years.

\section{Results and discussion}

LST maps (Fig.4, Fig.5) show that temperature values in the studied areas vary between 28 and $42^{\circ} \mathrm{C}$, temperatures values differ from season to another, with the presence of cold seasons such as summer 2002,2011 and 2014 where LST values vary between 28 to $36^{\circ} \mathrm{C}$ and also some warm seasons characterized by temperatures values that run between 36 and $42^{\circ} \mathrm{C}$ like summer 2000, 2000 and 2016. 
Boutaina Sebbah, Miriam Wahbi, Mustapha Maâtouk, Geographical Information System Tool Monitoring the Environmental Impact of Tangier Industrial Zones. Transactions on Machine Learning and Artificial Intelligence, Vol 5 No 4 August (2017); p: 795--802

In the first studied area (i.e. TFZ) and before the implantation of the industrial zone, the area tends to appears homogeneous in terms of LST values, from 2002 onwards it was noted the appearance of three major plants (i.e.YZAKI, S.E.B.N and Delphi) that appear as hot spots; they have in general temperature higher than thesurroundings area.

In the graph of LST variation (Fig.6); temperature varies in this areas between 28 and $43^{\circ} \mathrm{C}$, the three pics in the graph present LST values of major plants already cited. LST values have attend their maximum during 2013 which was a

relatively hot season; while the minimum values were recorded during summer of 2014, it is remarkable that the temperature between these pics decrease, and also when moving away from the TZF to the surrounding areas the LST decrease to $31^{\circ} \mathrm{C}$, note that these three factories that participate in the heating of TFZ area and also its environs are wiring plants specialized in the production of cables.

InMeghogha industrial zone, which is the oldest industrial area in Tangier city, results show that LST in this area is relatively higher than its environs, temperature values vary between 31 and $45^{\circ} \mathrm{C}$; with the presence of a major hot spot present 'Jacob Delafon', a plant which is specialized in the fabrication of sanitary equipment. LST graph in Meghogha industrial zone (Fig.7), results show that the maximum temperature values were recorded in summer 2013 while minimum values were recorded during summer 2014.

In both studied areas results shows that the major plants appear as hot spots even during the coldest seasons or the warmest ones, they appear $5^{\circ} \mathrm{C}$ warmer than their surroundings areas.

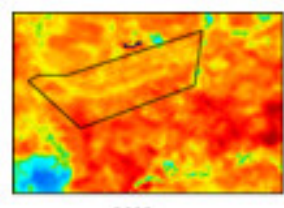

2000

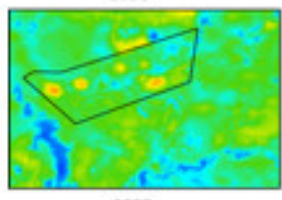

2009

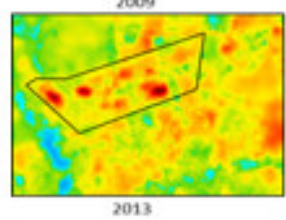

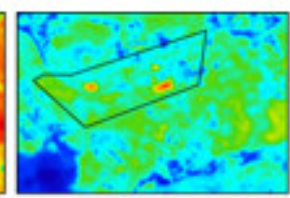

2002

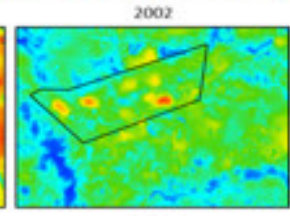

2010

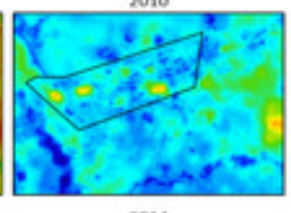

2014

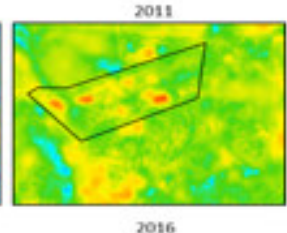

2016

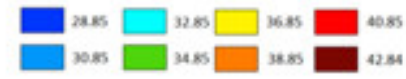

Figure 4 LST maps of Tangier free zone 


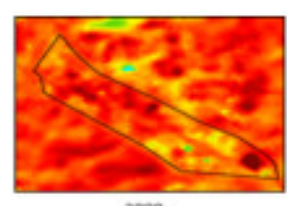

2000

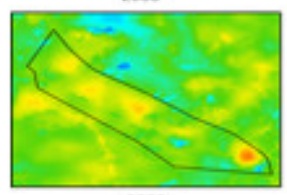

2009

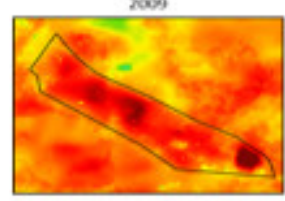

2013

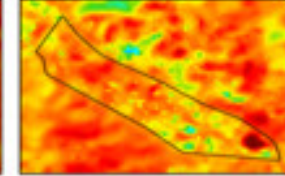

2001

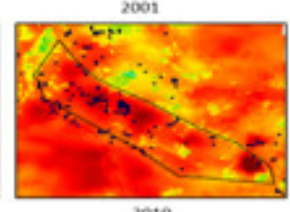

2010

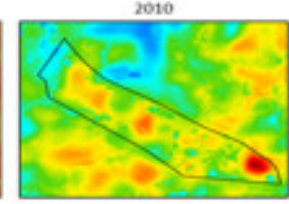

2014
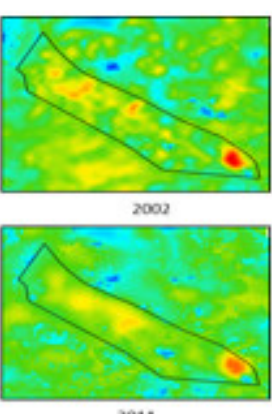

2011

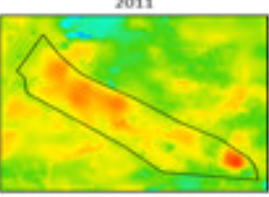

2016

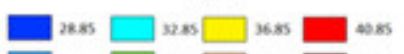

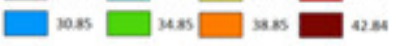

Figure 5. LST maps of Meghogha industrial zone

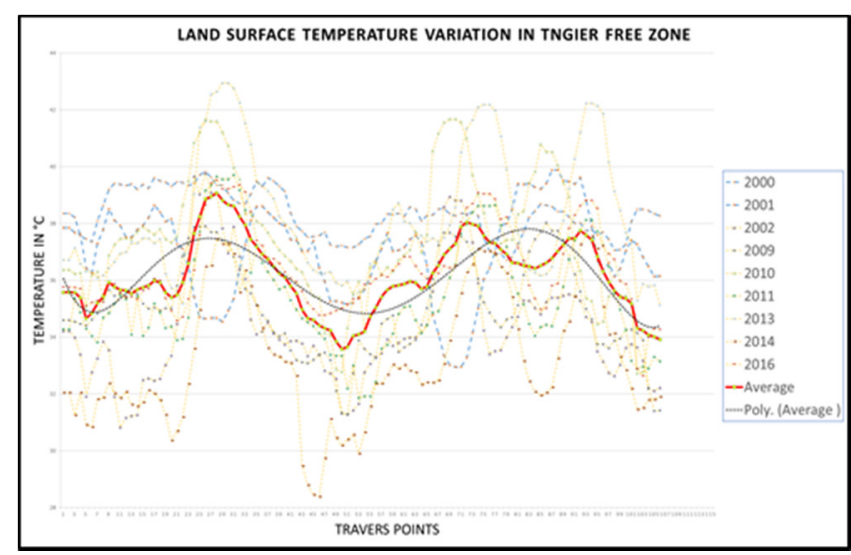

Figure 6. LST variation in Tangier free zone from 2000 to 2016

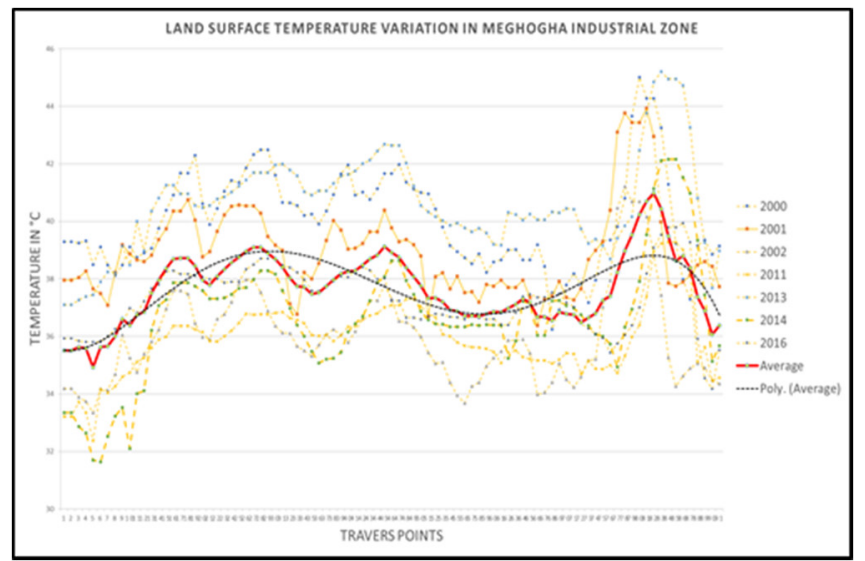

Figure 7. LST variation in Meghogha industrial zone from 2000 to 2016

5 Conclusion

This study has used a combination of remote sensing data and GIS tool to evaluate LST variation in two industrial zones of Tangier city, the obtained results has shown a difference of $5^{\circ} \mathrm{C}$ between industrial 
Boutaina Sebbah, Miriam Wahbi, Mustapha Maâtouk, Geographical Information System Tool Monitoring the Environmental Impact of Tangier Industrial Zones. Transactions on Machine Learning and Artificial Intelligence, Vol 5 No 4 August (2017); p: 795--802

zones and their surrounding areas, with the presence of some micro urban heat island presenting the major plants in industrial zones.Given the climate changes that induce temperatures raising, this phenomenon of micro urban heat islands could be more widespread in the surrounding areas and may have some drastic consequences, in particular citizens health status.

Thus, this industrial activity could not be stopped, view its primordial role in city development, but it is necessary to take into account the environmental aspect, in order to protect the surrounding areas, and reduce the temperature in industrial zones allto achieve a sustainable development of the city.

\section{REFERENCES}

[1] R. Anniballe, S. Bonafoni, and M. Pichierri, "Spatial and temporal trends of the surface and air heat island over Milan using MODIS data," Remote Sens. Environ., vol. 150, pp. 163-171, Jul. 2014.

[2] J. A. Sobrino, R. Oltra-Carrió, G. Sòria, R. Bianchi, and M. Paganini, "Impact of spatial resolution and satellite overpass time on evaluation of the surface urban heat island effects," Remote Sens. Environ., vol. 117, pp. 50-56, Feb. 2012.

[3] J. A. Voogt and T. R. Oke, "Thermal remote sensing of urban climates," Remote Sens. Environ., vol. 86, no. 3, pp. 370-384, Aug. 2003.

[4] Haut Commissariat au plan, "Population legale des regions, provinces, prefectures, municipalites, arrondissements et communes du royaume." 2014.

[5] "Royaume du Maroc - Centre d'Investissement de la Région Tanger Tetouan Al Hoceima." [Online]. Available: http://www.investangier.com/.

[6] M. L. Imhoff, P. Zhang, R. E. Wolfe, and L. Bounoua, "Remote sensing of the urban heat island effect across biomes in the continental USA," Remote Sens. Environ., vol. 114, no. 3, pp. 504-513, Mar. 2010.

[7] D. Zhou, S. Zhao, S. Liu, L. Zhang, and C. Zhu, "Surface urban heat island in China's 32 major cities: Spatial patterns and drivers," Remote Sens. Environ., vol. 152, pp. 51-61, Sep. 2014.

[8] J. Quan, Y. Chen, W. Zhan, J. Wang, J. Voogt, and M. Wang, "Multi-temporal trajectory of the urban heat island centroid in Beijing, China based on a Gaussian volume model," Remote Sens. Environ., vol. 149, pp. 33-46, Jun. 2014.

[9] C. Aniello, K. Morgan, A. Busbey, and L. Newland, "Mapping micro-urban heat islands using LANDSAT TM and a GIS," Comput. Geosci., vol. 21, no. 8, pp. 965-969, Oct. 1995.

[10] G. Chander, B. L. Markham, and D. L. Helder, "Summary of current radiometric calibration coefficients for Landsat MSS, TM, ETM+, and EO-1 ALI sensors," Remote Sens. Environ., vol. 113, no. 5, pp. 893-903, May 2009.

[11] United States Geological Survey, “Landsat Missions: Using the USGS Landsat 8 Product.” 2015.

[12] United States Geological Survey, “LANDSAT 8 (L8) Data users handbook." 2016.

[13] Q. Weng, D. Lu, and J. Schubring, "Estimation of land surface temperature-vegetation abundance relationship for urban heat island studies," Remote Sens. Environ., vol. 89, no. 4, pp. 467-483, Feb. 2004. 